\title{
EVALUATION OF THE TOXICITY OF EXTRACTS FROM GRAPE MARC POLAR
}

\section{Germanó, María José ${ }^{1}$, Muñoz, Marcos David ${ }^{2}$, Ramirez Darío Ceferino², Enriz Ricardo Daniel $^{1}$ and Giannini Fernando Ángel ${ }^{1}$ *}

${ }^{1}$ Area of General and Inorganic Chemistry. Universidad Nacional de San Luis. San Luis, Argentina.

${ }^{2}$ Laboratory of Experimental and Therapeutic Medicine. IMIBIO-SL-CONICET. San Luis, Argentina.

Article Received on 22 Jan. 2017,

Revised on 12 Feb. 2017, Accepted on 05 March. 2017 DOI: $10.20959 /$ wjpr20174-8027

\section{*Corresponding Author}

Germanó María José

Area of General and Inorganic Chemistry. Universidad Nacional de San Luis. San Luis, Argentina.

\begin{abstract}
Argentina is the major wine producer of south hemisphere, much of that production causes mainly two types of solids wastes, called marc and stems. Two of principal varieties of vine used in this region to the production of fine wine are Malbec and Syrah. The most important secondary metabolites in both wine and their by-products are the tannins and others phenolic compounds [anthocyanin, flavonoids, flavonols, stilbenoids (resveratrol) and phenolic acids] responsible for benefits attributed to human health. The extracts, to be used for raw material with pharmaceutics and/or food industrial propous, first must be verified their potencial toxicity. In this work, we presented the evaluation of toxicity of six marc polar extracts to various
\end{abstract} experimental models (crustaceans, fishes, and a cellular line) at concentrations up 1000 $\mu \mathrm{g} / \mathrm{cm}^{3}$, demonstrating that they do not cause toxicity to experimental models used.

KEYWORDS: Wine, Fish, Crustaceans, RAW cells, Viability.

\section{INTRODUCTION}

According to International Organization of Vine and Wine, Argentina is the major wine producer of south hemisphere with average production of $14.98 \times 10^{5} \mathrm{~m}^{3}$ per year; most of this production is generated in the Cuyo region (94\% of total, according National Institute of Viticiniculture - 2013). The winemaking causes mainly two types of solids wastes, called marc and stems, obtaining respectively $4 \mathrm{~kg}$ and $15 \mathrm{~kg}$ of each for $0.1 \mathrm{~m}^{3}$ of wine. Although 
there are a lot of vine varieties cultured as Malbec, Merlot, Cabernet Sauvignon, Lambrusco Maestri, Syrah, Chardonnay, Riesling, Torrontés, Tocai, Chenin and Suavignon blanc; two of principal vine varieties used to produce fine wine in the Cuyo region of Argentina are Malbec and Syrah.

The most important secondary metabolites in both wine and their by-products are the tannins and others phenolic compounds. The polyphenols are responsible of very biologics activities and benefits attributed to human health. ${ }^{[1,2,3]}$ Phenolic compounds are anthocyanin, flavonoids, flavonols, stilbenoids (resveratrol) and phenolic acids. ${ }^{[4,5,6]}$

There are multiple studies to assume that polyphenols would be responsible of beneficial effects on degenerative and cardiovascular disease,$^{[7,8,9]}$ and certain cancers ${ }^{[10,11]}$ due to act reducing oxidative stress in plasm and slow-down aging. ${ }^{[12,13]}$

Some raw material can be used to pharmaceutics and/or food industrial purposes, but first must be verified the potencial toxicity of them. This evaluation can be performed at differents levels of complexity, thus there are in vivo assays in differents experimental models, among which highlights, by its simplicity, economy and speed, indicatives assays that use fishes and crusaceans very used for our working group, ${ }^{[14,15,16]}$ as studies in mammals cells lines, which may be considered more conclusive.

The murine macrophages, involved in inflammatory response and oxidative stress; ${ }^{[17,18]}$ are an experimental model widely used in research because handling technique and its culture are standarized.

The objective of this work was to perform a series of toxicity testing of extracts from grape marc polar of two varieties of Vitis vinifera, Malbec and Syrah to experimental models of different complexity levels among them crustaceans, fishes and cell line murine macrophages RAW 264.7 to analyze their potential use due to important bioactivities previously reported. ${ }^{[19,20,21,22,23,24]}$

\section{MATERIALS AND METHODS}

\section{Samples}

Marc samples of strains mentioned, are recollected in Rodeo del Medio (Latitude: $-32,983^{\circ}$, Longitude $-68,650^{\circ}$ ), Mendoza, Argentina during the months of February and March 2011. 


\section{Obtaining of the different extracts}

Infusion was prepared adding $100 \mathrm{~cm}^{3}$ of boiling distilled water to $30 \mathrm{~g}$ of marc and was sonicated for $0.12 \mathrm{ks}$. It was filtered by Buchner and the process was repeated with the residual material, and it was placed in vials to cool and lyophilizing. This extract was denominated Extract-Aqueous Infusion (EAI). Later, with the residual material, a decoction is made during $0.9 \mathrm{ks}$ with $150 \mathrm{~cm}^{3}$ distilled water; this operation was repeated once more. It was placed in vials to cool and lyophilizing. This extract was denominated Extract-Aqueous Decoction (EAD).

For the methanolic extract, $30 \mathrm{~g}$ of dried plant material (marc) was macerated in $100 \mathrm{~cm}^{3}$ of methanol at room temperature for $0.9 \mathrm{ks}$ subjected to ultrasound. The liquid was filtered. This process was performed in duplicate. The solvent was evaporated under reduced pressure on rotavap, obtaining the dry extract named Extract-Methanolic (EM).

The extracts obtained, were dissolved in distilled water and sterilized with filters of $0.22 \mu \mathrm{m}$. They were named according to the variety and the method of production
A. MAD (Malbec-Aqueous Decoction)
B. MAI (Malbec-Aqueous Infusion)
C. MM (Malbec-Methanolic)
D. SAD (Syrah-Aqueous Decoction)
E. SAI (Syrah-Aqueous Infusion)
F. SM (Syrah-Methanolic Syrah)

\section{Acute toxicity to fish and crustaceans}

The technique recommended by the U.S. Fish and Wildlife Service ${ }^{[25]}$ has been modified in order to employ a smaller amount of testing compounds as it was already reported by our group. ${ }^{[15]}$ The animals and the solutions were placed in a $2 \mathrm{dm}^{3}$ capacity container, at controlled temperature $(296.15 \mathrm{~K})$ without aeration; thereby they were maintained during the measurements.

The assay begins with an initial exposure to extract at $500 \mu \mathrm{g} / \mathrm{cm}^{3}$ and continues for 3.456 ms. Every $86.4 \mathrm{ks}$ the number of dead specimens in each container were counted and then removed. The toxicity effect of extracts was evaluated in fish of the specie Danio rerio of 0.7 to $1 \mathrm{~cm}$ of size approximately. Ten organisms were exposed to each extract. This assay was 
already reported by our group for berberine, ${ }^{[26]}$ antifungal peptic novel and antifungal drugs commercial use. ${ }^{[15,16]}$

For crustaceans, the solution volume used was $100 \mathrm{~cm}^{3}$ and the exposure time $86.4 \mathrm{ks}$; with the initial exposure to extract at $500 \mu \mathrm{g} / \mathrm{cm}^{3}$.

\section{Citotoxicity to RAW 264.7 cell line}

The murine macrophage cell line (RAW 264.7) were cultured in DMEM (Sigma-Aldrich®St. Louis, MO 63178; USA) containing 10\% fetal bovine serum (Natocor ${ }^{\circledR}$-Tokio 415; Villa Carlos Paz; Argentina) (complete medium), and were grown at $310.15 \mathrm{~K}, 5 \% \mathrm{CO}_{2}$ in fully humidified air.

Citotoxicity of extracts to cell line was determined by assaying mitochondrial reduction of a yellow tetrazolium salt, 3-(4,5-dimethylthiazol-2-yl)-2,5-diphenyltetrazolium bromide (MTT), to purple formazan crystals. ${ }^{[27]}$

$1 \times 10^{5}$ cells/well were seeded in 96 well-plates and they were incubated with increasing concentrations of each extract during $86.4 \mathrm{ks}$. The extracts were evaluated at 10, 100 and $1000 \mu \mathrm{g} / \mathrm{cm}^{3}$ in complete medium. A parallel control incubating the cells with complete medium was performed.

The results were expressed as viability percentage (Mean \pm SEM) relative to control considered the latter generator $100 \%$ viability.

\section{Statistical analysis}

For the results of acute toxicity in fish and crustaceans Chi Square method was applied to analyze and compare the frequencies among mortality rates from acute toxicity of the extracts evaluated.

For studies to cell line, we determined the significance of differences between treatments and control by one-way ANOVA ( $\mathrm{p}<0.001)$ with Dunnett's post hoc testing using Graphpad 5.00 program for windows. The quantitative data are reported as the mean values \pm standard error of the mean (SEM) from three independent experiments $(n=6)$.

\section{RESULTS AND DISCUSSION}

The results obtained from toxicity assay to fish and crustaceans are shown in the Table $\mathbf{1 .}$ 
Table 1: Results of toxicity effects of extracts to crustacean and fish

\begin{tabular}{|l|c|c|}
\hline \multirow{2}{*}{ Extract } & \multicolumn{2}{|c|}{ Mortality Percentage at $\mathbf{5 0 0} \mathbf{\mu g} / \mathbf{c m}^{\mathbf{3}}$} \\
\cline { 2 - 3 } & Crustacean & Fish \\
\hline MAD & 0 & 0 \\
\hline MAI & 0 & 0 \\
\hline MM & 0 & 0 \\
\hline SAD & 0 & 0 \\
\hline SAI & 0 & 0 \\
\hline SM & 0 & 0 \\
\hline
\end{tabular}

The toxicity effects of grape marc extracts to fish and crustaceans are represented as mortality percentage.

None of the tested extracts generated acute toxicity to fish (Danio rerio) and crustaceans (Artemia salina) at the concentration tested $\left(500 \mu \mathrm{g} / \mathrm{cm}^{3}\right)$.

In the second stage of this work, and searching more conclusive experimental models, the extracts were subjected to studies of their toxicity on a murine macrophage cell line following the methodology described.

The Figure 1 represents the results obtained.
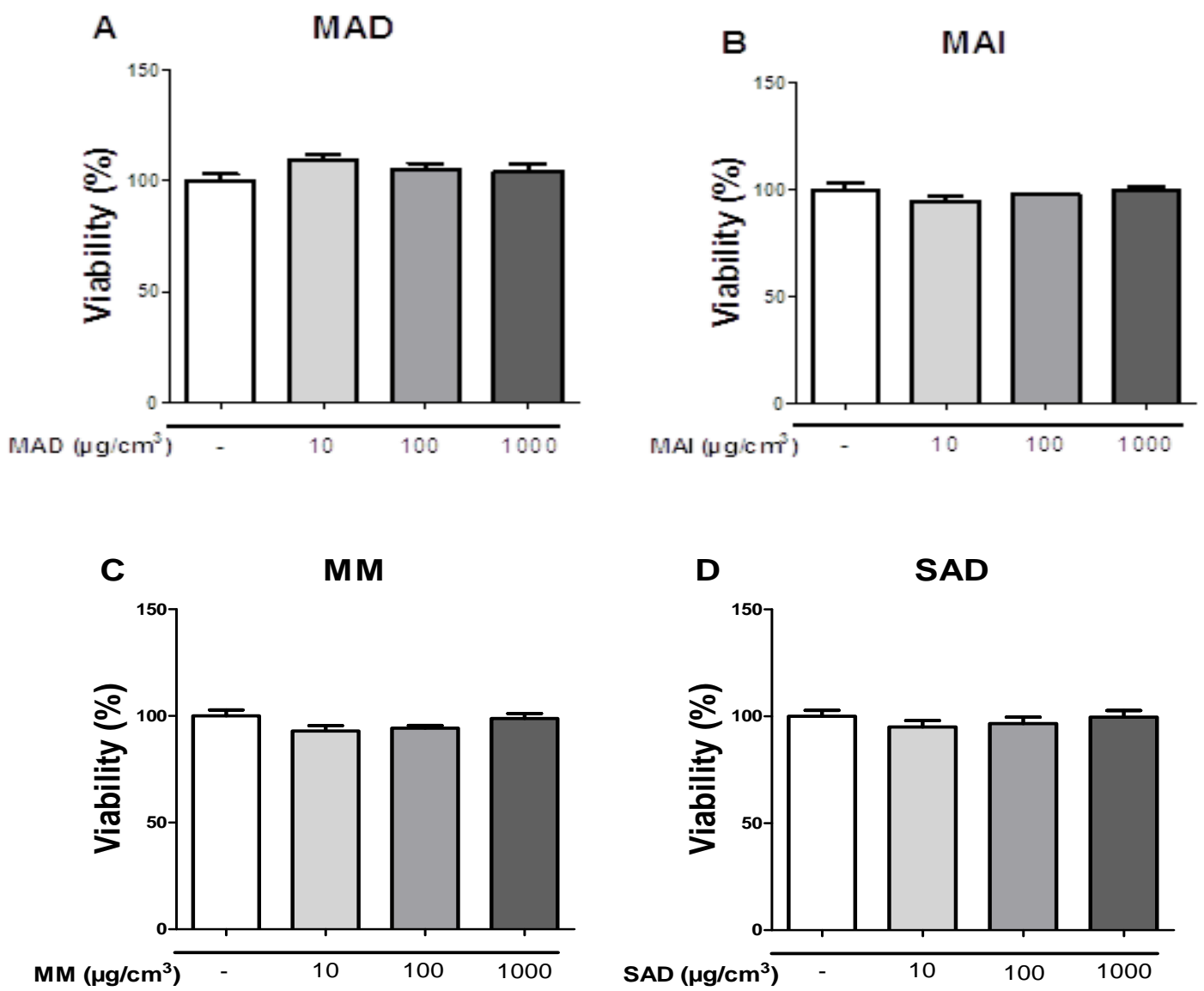

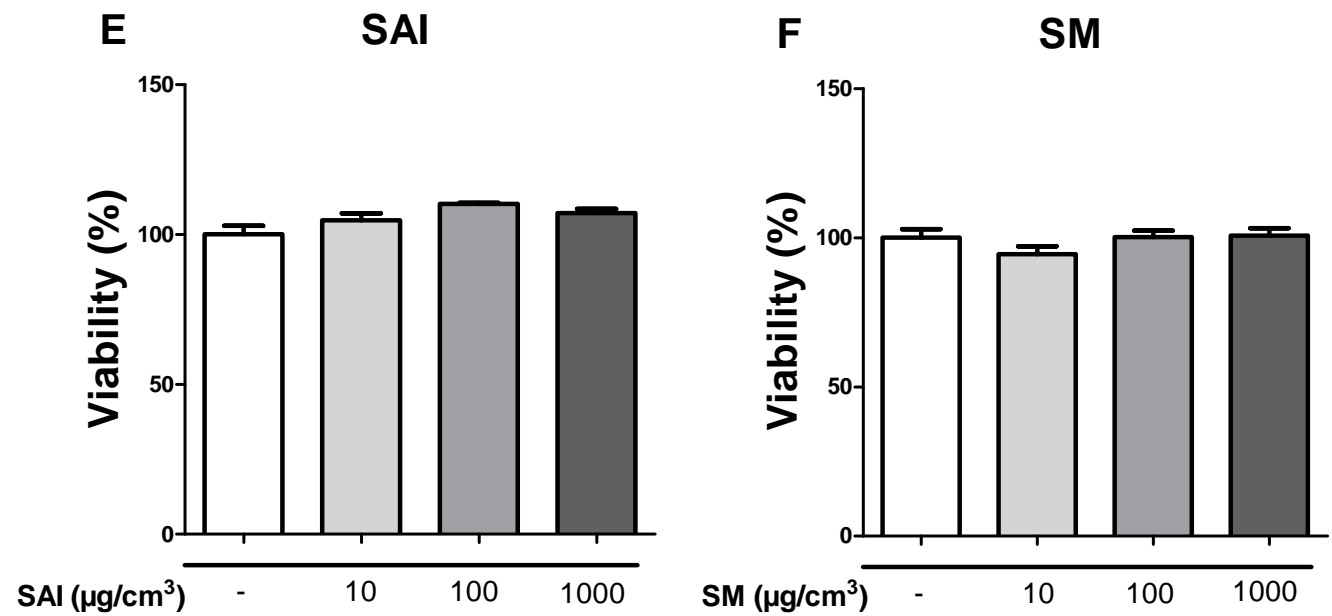

Figure 1: Citotoxicity effects of grape marc extracts. The extracts were assayed at different concentrations $\left(0,10,100\right.$ and $\left.1000 \mu \mathrm{g} / \mathrm{cm}^{3}\right)$ on $\mathrm{RAW} 264.7$ cell line, expressed as viability percentage (Mean \pm SEM) of triplicate.

The results show that all tested extracts do not exhibit toxicity on experimental models tested at concentrations up to $500 \mu \mathrm{g} / \mathrm{cm}^{3}$, it is very encouraging that observed in murine macrophage cultures where decrease in cell viability was not detected even at concentrations up to $1000 \mu \mathrm{g} / \mathrm{cm}^{3}$. There is a correlation among the results of toxicity to fish, crustaceans and cell lines.

\section{CONCLUSIONS}

Given that the extracts evaluated come from waste products in the wine industry, so it could be very advantageous to provide useful primarily in relation to health; and because no accused acute toxicity to these three experimental models, even at concentrations of 1000 $\mu \mathrm{g} / \mathrm{cm}^{3}$, they can be considered as potential resources for use in the pharmaceutical and/or food industry. Additionally it could be suggested as range limit in the evaluation of potential bioactivities a value of $1000 \mu \mathrm{g} / \mathrm{cm}^{3}$, mainly due to the assays on cell line.

\section{ACKNOWLEDGEMENTS}

Grants from Universidad Nacional de San Luis (UNSL), supported this work. R. D. Enriz is member of the Consejo Nacional de Investigaciones Científicas y Técnicas (CONICETArgentina). 


\section{REFERENCES}

1. Silva R, Cheynier V, Chemina A. Procyanidin dimers and trimers from grape seeds. Phytochemistry. 1991; 30(4): 1259-64.

2. Wada M, Kido H, Ohyama K, Ichibangase T, Kishikawa N, Ohba Y, Nakashima K. Chemiluminescent screening of quenching effects of natural colorants against reactive oxygen species: evaluation of grape seed, monascus, gardenia and red radish extracts as multi-functional food additives. Food Chem. 2007; 101(3): 980-6.

3. Shrikhande A. Wine by-products with health benefits. Food Res. Int. 200; 33(6): 469-74.

4. Dopico-García M, Fique A, Guerra L, Afonso, J, Pereira O, Valentão P, Seabra R. Principal components of phenolics to characterize red Vinho Verde grapes: Anthocyanins or non-coloured compounds?. Talanta. 2008; 75(5): 1190-202.

5. Novaka I, Janeiroa P, Serugab M, Oliveira-Brett A. Ultrasound extracted flavonoids from four varieties of Portuguese red grape skins determined by reverse-phase highperformance liquid chromatography with electrochemical detection. Anal. Chim. Acta. 2008; 630(2): 107-15.

6. Spáčil Z, Nováková L, Solich P. Analysis of phenolic compounds by high performance liquid chromatography and ultra performance liquid chromatography. Talanta. 2008; 76(1): 189-99.

7. Falchi M. Comparison of cardioprotective abilities between the flesh and skin of grapes. J. Agric. Food Chem. 2006; 54(18): 6613-22.

8. Shanmuganayagam D, Warner T, Krueger C, Reed J, Folts J. Concord grape juice attenuates platelet aggregation, serum cholesterol and development of atheroma in hypercholesterolemic rabbits. Atherosclerosis. 2007; 190(1): 135-42.

9. Olas B, Wachowicz B, Tomczak A, Erler J, Stochmal A, Oleszek W. Comparative antiplatelet and antioxidant properties of polyphenol-rich extracts from: berries of Aronia melanocarpa, seeds of grape and bark of Yucca schidigera in vitro. Platelets. 2008; 19(1): 70-7.

10. Tsang C, Higgins S, Duthie G, Duthie S, Howie M, Mullen W, Crozier A. The influence of moderate red wine consumption on antioxidant status and indices of oxidative stress associated with CHD in healthy volunteers. Br. J. Nutr. 2005; 93(2): 233-40.

11. God J, Tate P, Larcom L. Anticancer effects of four varieties of muscadine grape. J. Med. Food. 2007; 10(1): 54-9. 
12. Meyer A, Yi O, Pearson D, Waterhous A, Frankel E. Inhibition of human low-density lipoprotein oxidation in relation to composition of phenolic antioxidants in grapes (Vitis vinifera). J Agr. Food Chem. 1997; 45(5): 1638-43.

13. Jung K, Wallig M, Singletary K. Purple grape juice inhibits 7, 12-dimethylbenz [a] anthracene (DMBA)-induced rat mammary tumorigenesis and in vivo DMBA-DNA adduct formation. Cancer lett. 2006; 233(2): 279-88.

14. Bisogno F, Mascotti L, Sanchez C, Garibotto F, Giannini F, Kurina-Sanz M, Enriz R. Structure-antifungal activity relationship of related cinnamic acid derivatives. J Agr Food Chem., 2007; 55(26): 10635-40.

15. Mascotti M, Enriz R, Giannini F. Acute toxicity study of commercial antifungal drugs using Poecilia reticulata. Lat Am J Pharm. 2008; 27(6): 904-05.

16. Garibotto F, Garro A, Masman M, Rodríguez A, Luiten P, Raimondi M, Enriz R. New small-size peptides possessing antifungal activity. Bioorg Med Chem. 2010; 18(1): 15867.

17. Duffield J. The inflammatory macrophage: a story of Jekyll and Hyde. Clin Sci. 2003; 104(1): 27-38.

18. Chawla A, Nguyen K, Goh Y. Macrophage-mediated inflammation in metabolic disease. Nat. Rev. Immunol. 2011; 11(11): 738-49.

19. Comalada M, Camuesco D, Sierra S, Ballester I, Xaus J, Gálvez J, Zarzuelo A. In vivo quercitrin anti-inflammatory effect involves release of quercetin, which inhibits inflammation through down-regulation of the NF- $\kappa$ B pathway. Eur. J. Immunol. 2005; 35(2): 584-92.

20. Bralley E, Hargrove J, Greenspan P, Hartle D. Topical anti-inflammatory activities of vitis rotundifolia (Muscadine Grape) extracts in the tetradecanoylphorbol acetate model of ear inflammation. J. Med. Food. 2007; 10(4): 636-42.

21. Kar P, Laight D, Rooprai H,Shaw K, Cummings M. Effects of grape seed extract in Type 2 diabetic subjects at high cardiovascular risk: a double blind randomized placebo controlled trial examining metabolic markers, vascular tone, inflammation, oxidative stress and insulin sensitivity. Diabet. Med. 2009; 26(5): 526-31.

22. Terra X, Montagut G, Bustos M, Llopiz N, Ardèvol A, Bladé C, Blay M. Grape seed procyanidins prevent low-grade inflammation by modulating cytokine expression in rats fed a high-fat diet. J. Nutr. Biochem. 2009; 20(3): 210-8.

23. Gitto V, Germano-Garcia M, Ferersin G, Luna L, Ferrari M, Giannini F. Antioxidant activities of grape marc polar extracts. Rev. Biocell. 2013; 37(3): pA200. 
24. Bak M, Truong V, Kang H, Jun M, Jeong W. Anti-inflammatory effect of procyanidins from wild grape (Vitis amurensis) seeds in LPS-induced RAW 264.7 cells. Oxid Med Cell Longev, 2013; 2013: 1-11.

25. Johnson, W. W., \& Finley, M. T. Handbook of acute toxicity of chemicals to fish and aquatic invertebrates: summaries of toxicity tests conducted at Columbia National Fisheries. 1st ed, United State Fish and Wildlife Service. Research Laboratory: 1980, pp 1965-78.

26. Freile M, Giannini F, Pucci G, Sturniolo A, Rodero L, Pucci O, Balzareti V, Enriz RD. Antimicrobial activity of aqueous extracts and of berberine isolated from Berberis heterophylla. Fitoterapia. 2003; 74(7): 702-5.

27. Mosmann T. Rapid colorimetric assay for cellular growth and survival: Application to proliferation and cytotoxicity assay. J. Immunol. Methods. 1983; 65(1-2): 55-63. 